\title{
Design and additive manufacturing of brushless electric motor components
}

\author{
Camil Lancea ${ }^{1, *}$, Valentin-Marian Stamate ${ }^{1}$, Lucia-Antoneta Chicoș $^{1}$, Sebastian-Marian \\ Zaharia $^{1}$, Alin-Mihai Pop ${ }^{2}$, Ionut-Stelian Pascariu ${ }^{1}$, and George-Răzvan Buican ${ }^{1}$ \\ ${ }^{1}$ Transilvania University of Braşov, Manufacturing Engineering Department, 500036, B-dul Eroilor \\ nr. 29, Brasov, Romania \\ ${ }^{2}$ Transilvania University of Braşov, Department of Materials Science, 500036 B-dul Eroilor nr. 29, \\ Brasov, Romania
}

\begin{abstract}
The electric motor components are manufactured through the additive process of fused filament fabrication in order to verify the functionality of the electric motor assembly. This process was chosen due to the advantages it confers: fast obtaining of components, low manufacturing costs, no tools required for processing or for moulds manufacturing. Through the fused filament fabrication process, parts with complex geometries, which cannot be obtained by classical machining, can be manufactured. Due to the above-mentioned advantages, this technology is extremely useful for the manufacture and testing of prototypes. The paper aims to manufacture components of a brushless electric motor in order to verify the assembling compatibility and manufacturing accuracy.
\end{abstract}

\section{Introduction}

To combat both: pollution and the consumption of the limited fossil fuel resources, but also due to the increased reliability and efficiency of electric motors, recently, internal combustion engines have begun to be replaced, increasingly more, with electric motors. The largest share of the implementation of this solution is indisputably held by the automotive industry [1].

After developing various kinds of additive manufacturing processes, this type of engine has an increasing extent as the main propulsion system for a wide range of unmanned aerial vehicles (drones) [2]. This increased number and types of electric motors on the present market are primarily due to the substantial reduction of their manufacturing costs, by using additive manufacturing processes to build most of the motor's components [3].

Due to its capacity for direct digital manufacturing of end products AM opens new avenues for design solutions that are otherwise challenging or impossible to achieve when using conventional manufacturing techniques. Therefore, the evolution of AM has been recognized as a key enabling technology in a wide range of applications, some of which include the medical, aerospace, and automotive industries $[4,5]$. Another advantage of the AM relates to its low material waste and its very high flexibility.

\footnotetext{
*Corresponding author: camil@unitbv.ro
} 
The brushless direct current motor (BLDC) is a brushless electric motor that is controlled by a three-phase inverter [6]. Due to its outstanding performance, this kind of motor is the most widely used motor for electric vehicles. Among the advantages offered by this engine are robustness, simplicity, high efficiency, high power to a large torque to volume ratio, a very good efficiency over a wide range of speeds and torques, and low noise [7-9]. The main components of the motor are: the stator, rotor, shaft, coils, outer casing, and bearings.

The recent development of mechatronic systems, especially in the automation of technological and industrial processes, have led to the intensive development of brushless direct current (BLDC) motors supplied by electronic commutators and excited by permanent magnets [10]. Due to the advantages mentioned above, BDC engines have been used as power supplies for CNC machines, or industrial robots, as well as from the development of essential techniques for motion control systems, such as airplanes, drones, or vehicles, to industrial and military applications $[11,12]$.

This paper aims to design some BLDC engine parts in order to verify their assembly possibilities in order to mount the engine on an unmanned aerial aircraft.

\section{Materials and Methods}

PLA (Polylactic Acid) material was chosen for manufacturing all brushless electric motor components. The parts were designed as solid models, within the Part module of the SolidWorks software system.

\subsection{Design of brushless electric motor components}

All the brushless electric motor components, which are analysed in this study, were created with SolidWorks 2016 software system. Figure 1 presents the designed geometry of the main components of the electric motor: the stator winding (Fig. 1-a) and the rotor with magnets (Fig. 1-b).

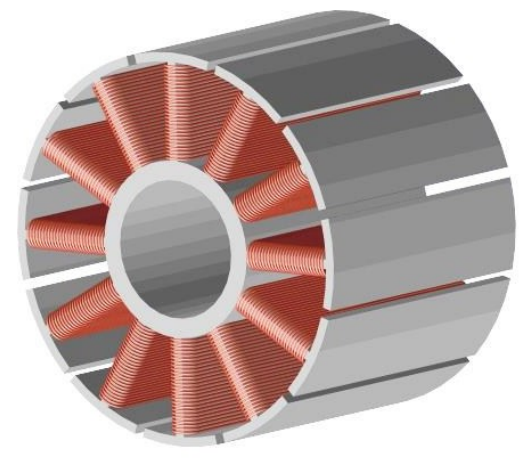

a

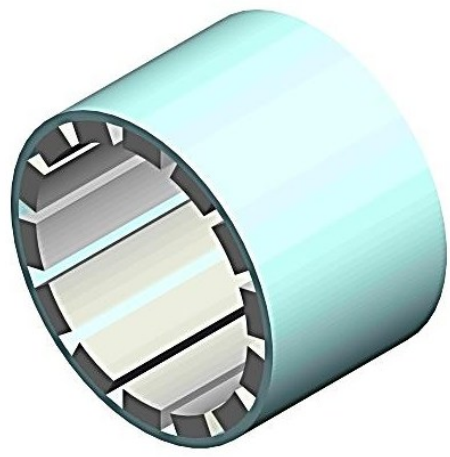

b

Fig. 1. The designed geometry of the main electric motor components:

$\mathrm{a}-$ the stator winding and $\mathrm{b}-$ the rotor with magnets

The designed motor housing is presented in figure 2, as follows: the right case (Fig. 2-a); left case (Fig. 2-b).

The secondary components of the motor were also modelled: shaft, ball bearings, screws, and nuts. 
The chosen material, for building all the motor components, was PLA (Polylactic Acid). This material was chosen due to its advantages: PLA a biodegradable polymer made from renewable sources, with good mechanical and thermal properties.

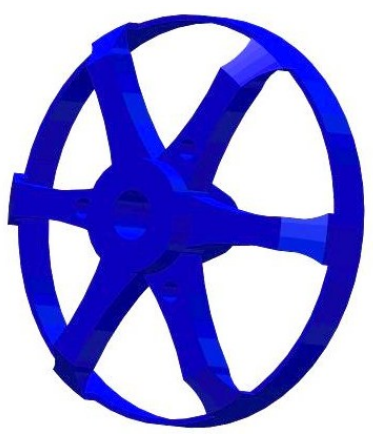

a

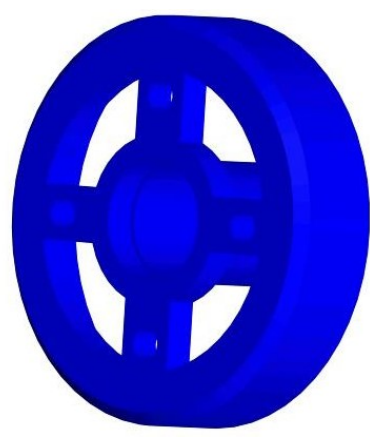

$\mathrm{b}$

Fig. 2. The designed geometry of the electric motor housing: $\mathrm{a}$ - the right case and $\mathrm{b}$ - the left case

The assembled 3D model of the brushless electric motor is shown in Figure 3. In order to stiffen the structure of the electric motor, additional housings were added, as shown in figure 1-b.

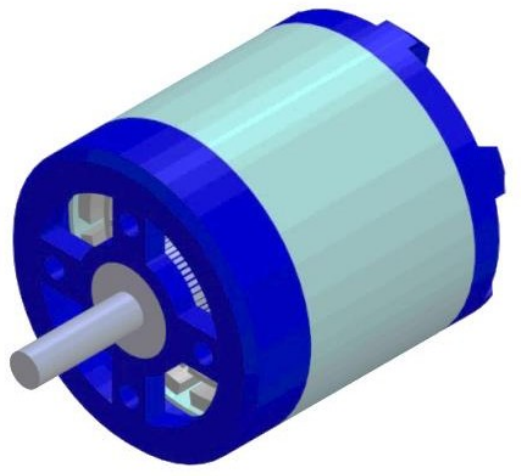

a

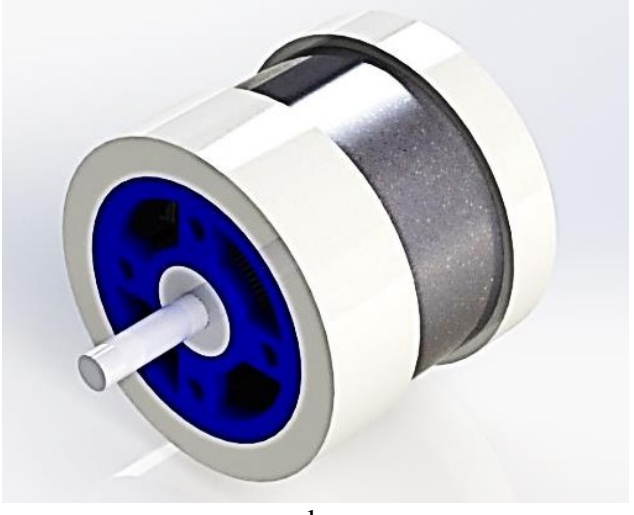

b

Fig. 3. The 3D model of brushless electric motor:

$\mathrm{a}$ - the assembled motor and $\mathrm{b}$ - additional housings for improving the structure rigidity

The characteristics of the brushless electric motor components are shown in Table 1.

Table 1. The brushless electric motor components

\begin{tabular}{|c|c|}
\hline Components & Value \\
\hline Stator Diameter [mm] & 40 \\
\hline Stator Thickness [mm] & 30 \\
\hline Number of Stator Slots & 12 \\
\hline Number of Stator Poles & 14 \\
\hline Rotor Diameter [mm] & 57 \\
\hline Body Length [mm] & 63 \\
\hline Weight [g] & 369 \\
\hline Maximum Lipo Cell & $6 \mathrm{~S}$ \\
\hline Neodymium Magnets Dimensions [mm] & $30 \times 7.5 \times 2.5$ \\
\hline Propeller [inch] & $15 \times 8$ \\
\hline
\end{tabular}




\subsection{Manufacturing parameters of motor components}

The components of the electric motor were manufactured using the BCN3D Epsilon W50 printer. As building material was used PLA (Polylactic Acid) because this kind of filament is very easy to use. The mechanical and thermal properties of the Ultrafuse PLA filament, supplied by the manufacturer - BASF 3D Printing Solutions GmbH, are shown in Table 2.

Table 2. Mechanical and thermal properties of the PLA filament used in 3D printing of electric motor components [13]

\begin{tabular}{|c|c|c|}
\hline Mechanical and Thermal Properties - PLA & Value & Standard \\
\hline Tensile strength [MPa] & 48 & ISO 527 \\
\hline Elongation at Break [\%] & 21.9 & ISO 527 \\
\hline Young's Modulus [MPa] & 3166 & ISO 527 \\
\hline Flexural Strength [MPa] & 92.4 & ISO 178 \\
\hline Flexural Modulus [MPa] & 2823 & ISO 178 \\
\hline Flexural Strain at Break [\%] & 4.3 & ISO 178 \\
\hline Impact Strength Charpy $\left[\mathrm{kJ} / \mathrm{m}^{2}\right]$ & 20.4 & ISO 179 \\
\hline Melting Temperature $\left[{ }^{\circ} \mathrm{C}\right]$ & $170-180$ & ISO 11357-3 \\
\hline Glass Transition Temperature $\left[{ }^{\circ} \mathrm{C}\right]$ & 63 & ISO $11357-2$ \\
\hline
\end{tabular}

The LightWeight PLA LW-PLA filament (Gray Silver and Natural) was used for the upper casings. This type of filament uses active foaming technology to obtain light 3D printed parts with low-density.

For building the motor components were used the high-quality $3 \mathrm{D}$ printer: $\mathrm{BCN} 3 \mathrm{D}$ Epsilon W50. The innovative approach of this printer is characterized by its dual thermoplastic extrusion and a manufacturing volume of $420 \mathrm{~mm} \times 300 \mathrm{~mm}$ x $400 \mathrm{~mm}$.

The manufacturing parameters, of the thermoplastic extrusion process, of the electric motor components, are presented in table 3.

Table 3. 3D printing parameters of the brushless electric motor components

\begin{tabular}{|c|c|}
\hline Parameter & Value \\
\hline Layer height $[\mathrm{mm}]$ & 0.1 \\
\hline Infill [\%] & 100 \\
\hline Print speed [mm/s] & 60 \\
\hline Travel speed [mm/s] & 200 \\
\hline Printing temperature $\left[{ }^{\circ}\right]$ & 200 \\
\hline${\text { Bed temperature }\left[{ }^{\circ}\right]}[\mathrm{mm}]$ & 60 \\
\hline Hotend $[\mathrm{mm}]$ & 0.4 \\
\hline Filament diameter $[\mathrm{m}]$ & 2.85 \\
\hline
\end{tabular}

\section{Manufacture and assembly of electric motor components}

A PLA filament and the software system specific to the BCN3D Epsilon W50 printer (Fig. 4) were used to manufacture the rotor and the two housings (right case and left case). For setting the manufacturing parameters, in a computer-aided mode [14], was used the BCN3D Cura 3.4.1 printer software system, that converts the digital model into a set of instructions for the printer. The manufacturing time by the thermoplastic extrusion process of the two housings and the rotor was 5 hours and 34 minutes.

It is well known that the motors on unmanned aerial aircraft have a high level of vibration that affects flight control and manoeuvrability. In order to reduce the vibration level in the housing area, it was decided to cover them with 3 components manufactured through a thermoplastic extrusion process, made of LightWeight PLA LW-PLA filament. Thus, the BCN3D Epsilon W50 printer was used to build all these components. 


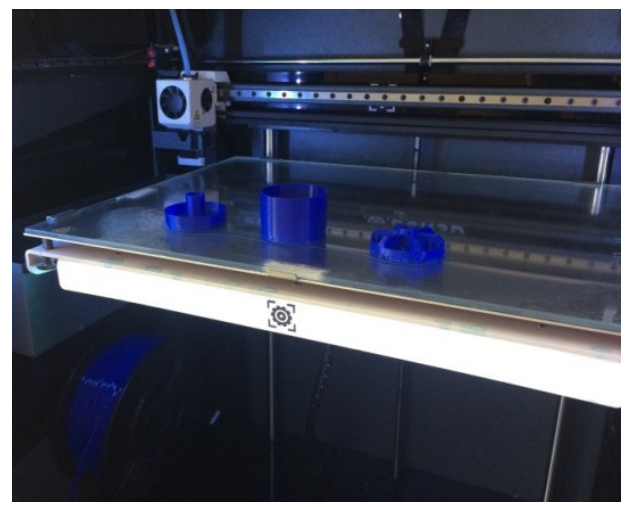

Fig. 4. Housing and central part of the electric motor, 3D printed

After obtaining all the motor components, the next step was to build the assembly (Fig. 5) in order to identify if any errors occurred within the design phase. In the first stage, the centring and fixing of the shaft on the right side cover was checked. The winding support was fixed on the shaft. Afterward, 2 radial ball bearings were inserted in the special slot provided in the right cover. Due to their complexity and high precision of execution, it was decided that the stator and winding should be manufactured by a specialized manufacturer.

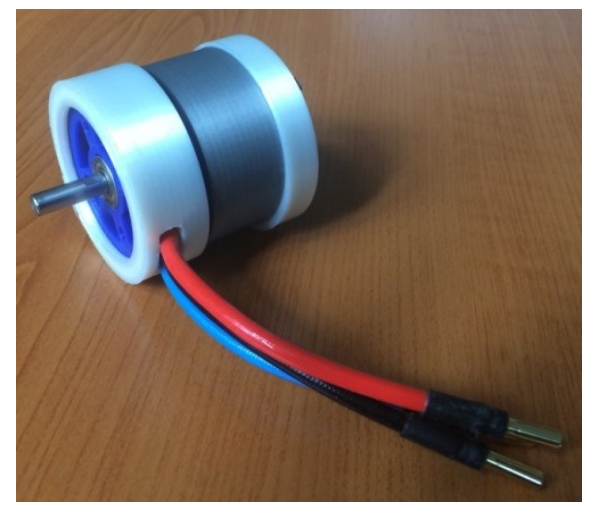

Fig. 5. The electric motor assembly

The stator component contains 12 brackets wound with $0.25 \mathrm{~mm}$ diameter copper wire. All the 14 magnets were glued to the rotor housing with a spacer device. The magnets were designed in order to comply with the configuration of a brushless electric motor. The motor housing is fixed by gluing it to the guide shoulder of the right cover. Next, the assembly of the left cover, provided with a slot for removing the three wires follows. These wires are obtained from the pairing of 4 coils on the stator.

The next stage of the assembling process is to secure the left cover to the motor shaft, by means of two M4 screws. The guide bearing of the stator cover is also fixed inside the left cover. On the left cover of the stator, in the 4 threaded holes, the part that allows the positioning of the motor to the structure of the aircraft is secured, through screws. The three connectors will be connected to electronic support controlled for the start-stop and speed adjustment functions of the electric motor.

After assembling all the designed components (Fig. 5) no errors were identified in the design phase which means that the designed parts can be printed on metal powder. 


\section{Conclusions}

The manufacture of components using fused filament fabrication is a challenge in the coming years for unmanned aircraft manufacturers. This manufacturing process has low costs, is easy to be used and offers the possibility of making complex structures in a very short time.

An interesting and challenging field refers to the manufacture of unmanned aerial aircraft components and models using $3 \mathrm{D}$ printing processes with material extrusion. The manufacture of components for unmanned aerial aircraft, through the thermoplastic extrusion of filament, in order to test their assembly and functionality is very efficient and can be done in a short time, having as advantages the simplicity of the manufacturing and assembly process, but also the elimination of moulds costs.

The electric motor, presented in this study, which was designed and built, only with CAD software and a $3 \mathrm{D}$ printer, is clear proof that a propulsion system can be manufactured, almost completely, using the fused filament fabrication.

After designing, manufacturing and assembling the brushless electric motor components, it was found that the geometric and dimensional accuracy of the designed components complied with all assembly restrictions. Also, the material that was chosen for the building the components were suitable for the easy assembly of the electric motor.

Acknowledgment: This work was supported by a grant of the Romanian Ministry of Education and Research, CCCDI - UEFISCDI, project number PN-III-P2-2.1-PED-2019-0739, within PNCDI III.

\section{References}

1. A. Erd, J. Stoklosa, Energies, 13 24, 6738 (2020)

2. L. Badum, B. Leizeronok, B. Cukurel, J ENG GAS TURB POWER, 143 2, 021006 (2021)

3. C. Silbernagel, I Ashcroft, P. Dickens, M. Galea, Addit. Manuf., 21 395-403 (2018)

4. P.S. Ghahfarokhi, A. Podgornovs, A. Kallaste, A. J. M. Cardoso, et al., IEEE Access, 9 36368-36381 (2021)

5. P. S. Ghahfarokhi, A. Podgornovs, A. Kallaste; A. J. Marques Cardoso et al., IEEE Access, 9 36368-36381 (2021)

6. Y. Uta Nugraha, A. Cahyadi, J. Raharjo, M. Nur Yuniarto, et. all., IOP Conf. Ser.: Mater. Sci. Eng. 694012007 (2019)

7. H-C Yua, C-S Jangb, W Y Peng, Mech Mach Theory, 84 134-144 (2015)

8. C. He, T. Wu, Energies, 11(6), 1360 (2018)

9. J. Feng, K. Liu, Q. Wang, IET Electr. Power Appl., 12 405-414 (2018)

10. H. Stakhiv, O. Solomchak, M. Stepien, P. Lasek, XI International Conference on Electrical Power Drive Systems (ICEPDS), pp. 1-5 (2020)

11. W.L. Soong, G.B. Kliman, R.N. Johnson, R.A. White, et al., IEEE T IND APPL, 36, 3, 706-713 (2000)

12. D. Di Giovanni, F. Fumian, A. Malizia, J INSTRUM, 14 C03006 (2019)

13. https://s.cdnmpro.com/490505258/custom/prod/1_fisa_tehnica_1199.pdf

14. C. Lancea, I. Campbell, L. Chicos, S. M. Zaharia, Polym. J., 12(12), 2767 (2020). 